\title{
Carlos Rincón (1937-2018): motivos para el recuerdo y el olvido
}

\author{
Alejandro Sánchez Lopera / Investigador independiente
}

Para despedir a Carlos Rincón, me gustaría evocar la imagen del cruce de caminos. Rincón es, quizás junto a Rafael Gutiérrez Girardot, el intelectual colombiano más importante del siglo XX a nivel global. A pesar de ello, los caminos de su obra han sido muchas veces poco andados y, otras más, clausurados. Su muerte, el 24 de diciembre de 2018 en Berlín, nos invita a cruzarnos en su camino para entrever qué rutas habría que desandar, cuáles se podrían bifurcar, y cuáles otras volver a andar. No se sabe a dónde conduce este cruce de caminos, pues sólo los lectores actuales y futuros de Rincón podrán catalizar las consecuencias de su trabajo, su lucidez y altibajos.

Pues, ¿qué hacía un latinoamericano como Rincón traduciendo tempranamente a Lyotard, Benjamin, Bajtin, Foucault y Adorno, desplazando el punto de vista desde las influencias hacia la estética de la recepción, al tiempo que fungía como asesor del Ministro de Cultura Ernesto Cardenal en el Ministerio de Cultura en Managua? Profesor emérito de la Freie Universität de Berlín, en Rincón se mezclan diferentes continentes y experiencias que terminaron perfilando una presencia incómoda y, por momentos, indeseable en algunas academias.

Sus textos, tal como él mismo nos lo cuenta en "Celebración y escarnio del Conde de Cartagena, General Pablo Morillo", parecen más materiales para pensar, en contra de la similitud, la identidad y el origen - rasgos tan afectos al pensamiento latinoamericano-_: "el origen encierra en sí el movimiento circular, de modo que cuanto de él proviene, a él retornaría: donde domina el origen no hay lugar para lo nuevo" (2014b, 135). De ahí que en Rincón no tenemos, primer camino, la curiosa y manida versión latinoamericana del eterno retorno (los pueblos que no conocen su historia están condenados a repetirla) sino, como veremos, la crítica a una repetición sin diferencia.

El segundo es por ende un camino a través del cual se desestructuraba lo referencial y lo representativo. La obra de Rincón explora y se sitúa en ese lugar donde lo individual y lo colectivo se entrelazan y, al mismo tiempo, se deshacen. De allí el estilo heterológico de su escritura. A su manera, Rincón hace parte del desplazamiento desde la representación política hacia la experiencia, desde quién es el actor primario (la masa, el subalterno, la clase) y sus medios (el libro, el testimonio) al problema del sujeto. Es decir, textos suyos como La no simultaneidad de lo simultáneo y García Márquez, Hawthorne, Shakespeare, De La Vega \& Co, así como Íconos y mitos culturales en la invención de la nación en Colombia y Avatares de la memoria cultural en Colombia, expresan la búsqueda de alternativas a la dialéctica tanto en el campo conceptual como en el político en América Latina.

Finalmente, el tercer camino conduce a algunas de las interferencias y prohibiciones que se tejen entre literatura y crítica. Más que usar la teoría social para leer la literatura, el intento de Rincón, nacido en Bogotá en 1937, fue traer la literatura a la teoría social para leer ésta última y, sobre todo, para leer la realidad. De ahí el lugar primordial que ocupó Jorge Luis Borges en sus textos - y, quizás en parte por eso, el lugar esquivo de los textos de Rincón en la crítica literaria latinoamericana y el llamado "latinoamericanismo" producido en los Estados Unidos. Borges, y el recurso a autores partícipes de la flecha lanzada contra la representación (Deleuze, Baudrillard y Foucault), imprimirán un doble estigma en su obra: "posmoderna" y "posestructuralista". En efecto, a pesar de haber sido un visitante frecuente en Norteamérica, y haber sido profesor visitante en Stanford (2006-2008) y Harvard (2000), los textos de Rincón casi no figuran en los currículos de estudios literarios en Estados Unidos. Tampoco se asoman con frecuencia en los de Latinoamérica. Entre Borges y la invisibilidad de Rincón en las Américas encontraremos, como veremos, una de las razones para el olvido de este último, así como una posible valoración política de su trabajo.

$$
* * *
$$

Dos hechos coinciden con el año de nacimiento de Rincón en 1937: la destitución del político republicano radical Jorge Eliécer Gaitán como alcalde de Bogotá y la inauguración del "Monumento a María” o "Monumento a Jorge Isaacs" en Cali. El primer hecho abre la puerta a explorar uno de los tópicos recurrentes en Rincón: la auto-monumentalización de Bogotá como Atenas sudamericana. Al segundo, la coronación de Isaacs y su novela, Rincón dedicará parte de su ejercicio de desmontaje, incluyendo un libro donde se compilaron las intervenciones del "juicio" televisivo sobre la novela, el cual fue transmitido por televisión colombiana en 1957 (2018a). 
Gaitán, político popular de una izquierda no comunista, había sido designado por el gobernador de Cundinamarca, Parminio Cárdenas, como alcalde de Bogotá — ciudad a la que nunca denominó, por supuesto, Atenas, salvo para criticar precisamente su semblante nada humano. En medio de una serie de ambiguas políticas por un lado antielitistas y, por el otro, higienistas (en una suerte de ambigua aristocracia popular), Gaitán es destituido por el gobernador Cárdenas, a sólo seis meses de la celebración de los 400 años de la ciudad. Once años más tarde, el 9 de abril de 1948, Gaitán sería asesinado, ad portas de convertirse en presidente, para trastocar irreversiblemente la imagen de Atenas en una Bogotá en llamas: Atenas incendiada, en lo que se conoce como "El Bogotazo". En ese momento, se estaba celebrando en Bogotá la IX Conferencia Panamericana, antesala del Pacto de Bogotá y de la Organización de Estados Americanos OEA, por lo que cabe preguntar si era sólo una o varias Atenas las que se estaban incendiando en ese momento. ¿Cómo imaginó Rincón esta posible reduplicación de Atenas?

En la genealogía que traza sobre la consigna de la Atenas, involucra no una sino varias Atenas a lo largo de las Américas: al menos Boston y Bogotá. Es precisamente en Boston donde va a publicar, en inglés y en español, su avance investigativo sobre "Las tres Atenas". ¿La tercera? Berlín.

En Prusia y en Massachusetts, a comienzos del siglo XIX, mucho antes de que surgiera como la fórmula la Atenas de Suramérica, se había intentado crear casi simultáneamente imaginarias réplicas de Atenas. En esas dos sociedades preindustriales, en la tensión entre imaginación cívico-urbana y diversas formas de imaginario de orden simbólico, mítico y utópico, Berlín fue das Spree-Athen, la Atenas a orillas del río Spree, y Boston se llamó the Athens of America (2003 s/p).

Rincón conocía bien tres de esas pretendidas Atenas. Entre 1970-76, había sido asistente científico en el Instituto de Investigaciones Literarias de la Akademie der Wissenschaften de Berlín. Desde 1990, antes de ser nombrado profesor emérito allí mismo en 2003, fue profesor titular de Latinoamericanística en el Lateinamerika-Institut de la Freie Universität en la misma ciudad. El capítulo alemán sobre el impacto, decurso y dificultades de la obra de Rincón está aún por escribirse; baste mencionar por ahora, como síntoma, el que ninguno de sus libros a partir de la década del 70 haya sido traducido al alemán. Así mismo, Rincón había sido visitante de la Universidad de Harvard en el año 2000, en Boston, denominada The Athens of America por William Tudor en 1819. Esta denominación, anterior a la de Bogotá, ya portaba diversas aporías: "en situaciones de crisis de legitimidad, la estética neoclásica las dotó en forma tangible de un árbol genealógico, para postular una continuidad cultural que, de hecho, se encontraba interrumpida" (Rincón, 2003 s/p).
De vuelta a Colombia, entre 1995 y 1996, como director del Programa Internacional Interdisciplinario sobre Estudios Culturales en América Latina, había coordinado una serie de simposios internacionales realizados en Bogotá y Cartagena sobre estudios literarios y culturales, la nueva novela histórica en América Latina, y sobre teorías de la cultura y estudios de comunicación. Rincón también había gozado de diversas instancias investigativas en Bogotá a través del programa Johann Gottfried Herder-Stiftung (DAAD) entre 2008 y 2016, fruto del cual fueron publicados dos de sus últimos libros de autor en Colombia. Sobre ellos volveremos al final del texto, pues constituyen instantáneas de lo vivido en Colombia obturadas desde el ángulo de una estética política.

Como en toda repetición basada en la semejanza, como en todo simulacro, en el caso de las Atenas no hay forma de hallar el original: lo que hay son réplicas de réplicas, farsas, comienzos en lugar de origen. Así, en lo que llama "la multiplicación de las Atenas", Rincón nos cuenta cómo la automonumentalización de Bogotá como Atenas no fue más que un soberbio acto colectivo fallido, retratado a fines de 1980 por Gustavo Zalamea en una serie de óleos en los que lleva el mar a la Plaza de Bolívar, haciendo naufragar allí al Capitolio Nacional. Es decir que la Atenas andina no tenía una orilla que contenía a un río como Berlín, sino que había sido inundada por el mar (Zalamea pintó en ese mar, incluso, a Moby Dick, la ballena de Herman Melville). La plaza de Bolívar, entonces, no es una réplica del ágora ateniense: es la plaza del naufragio, escribe Rincón (2003 s/p).

El segundo hecho sucedido en 1937 nos adentra en otro simulacro —otro "acto de reconciliación fallido"-: la apoteosis de Jorge Isaacs. Este fiasco está compuesto de diferentes escenas: la coronación fallida de María como "clásico nacional"; la tardía compra por parte del Estado de la Hacienda El Paraíso, escenario del idilio entre Efraín y María y, finalmente, el "juicio televisivo" sobre la novela en 1957. A la par de enseñar en el Seminario Andrés Bello del Instituto Caro y Cuervo y en el Departamento de Filosofía de la Universidad Nacional de Colombia, hay un hecho interesante que sirve como puente: Rincón fue encargado de la Dirección de la Televisión Educativa en la Televisora Nacional entre 1960 y 1961, pocos años después del juicio televisivo.

El juicio, televisado en seis emisiones por televisión nacional entre enero y febrero de 1957, se componía de un jurado, un acusador y defensor, y un fallo. Ahora, ¿cuál era el crimen? ¿Cuál el señuelo? Y, ¿quién era el (o la) culpable, y culpable de qué? Estamos ante una suerte de auto-posición - ya mediática - de un origen: un majestuoso simulacro que incluyó (¿cómo no?) una encuesta con escritores de la época, entre ellos el crítico Hernando Téllez, de quien Rincón publicará las obras completas en el año de 2016.

"Extrañeza, asombro e hilaridad" eran reacciones esperadas, nos dice Rincón, refiriéndose a lo que provocaban en él 
y en el grupo de estudiantes con los que estudiaba los materiales de esta "llamada al banquillo". Sin embargo, lo más escandaloso era que en este tribunal simulado, al igual que en el funeral de Isaacs y la "reconstrucción" de la hacienda, no aparecía un hecho decisivo: que El Paraíso era la casa de una hacienda esclavista. Al referirse a los argumentos ofrecidos por defensores y acusadores de María en el juicio medial), Rincón escribe:

$\mathrm{Su}$ primera premisa parecía haber consistido en eludir de forma sistemática - ¿qué clase de censura podía impedirlo? - toda alusión a los costos en democracia, republicanismo, moral pública, devastaciones sociales y económicas que había tenido, a más tardar desde la misma década de 1830 , la reincorporación a la Nueva Granada de la esclavocracia separatista del Cauca. (2018a, 12)

Precisamente a partir de esa constatación es que se le puede devolver la pregunta a Rincón, pues, ¿qué necesidad habría de monumentalizar la atrocidad, estableciendo la hacienda El Paraíso como espacio oficial? ¿No se están, acaso, derribando y desfigurando esos símbolos que, en efecto, re-presentan la infamia? El simulacro del juicio televisivo concluyó con el veredicto emitido por la Academia Colombiana de la Lengua, que iniciaba recordando que el juicio fue realizado "por cuenta de una importante firma comercial" (2018a, 101). Y sentenciaba: "muchos espectadores asistieron al desenvolvimiento de un juicio que resultó desfavorable para aquella obra literaria excelente y no perecedera" (101). Acto seguido, la Academia pasa a transcribir dos apartes de prensa que evocan el carácter "inmortal" del libro, y el carácter "extravagante" y "snob" del jurado (101-104).

Tres son las claves que ofrece Rincón para entender las razones del juicio: primero, replicar el modelo de Hollywood con sus ejemplos logrados de la fascinación que ejercen los tribunales televisados. Segundo, simular la discusión razonada que permitiría valorar, por parte de los críticos de entonces, la obra de Isaacs por fuera de la Academia Colombiana de la Lengua con sus miembros de linajes perpetuos. Finalmente, una motivación de enormes proporciones, tan grande como Moby Dick en el mar de la Plaza de Bolívar, pero aún así invisible:

Pero existía también una preocupación ética real, que se discutía en privado: ¿ante qué tribunales colombianos era menester que algún día comparecieran, si se trataba de delitos y penas, políticos como José María Villarreal, José Antonio Montalvo, Luis Ignacio Andrade y todos los demás responsables intelectuales de la violencia de la última década, junto a sus criminales ejecutores materiales, lo mismo militares que civiles? $(2018 \mathrm{a}, 116)$
Ya para entonces, en 1957, la postulación de Bogotá como Atenas de Sudamérica era no sólo un anacronismo, y un disparate, sino además un manto tendido para intentar cubrir una ciudad y un país ensangrentado a cuál más. Para la siguiente década, el itinerario de Rincón incorporará dos nuevas ciudades situadas fuera del triángulo de las Atenas: Managua y Caracas.

$* * *$

La década de 1970 supone un decantamiento en la orientación de Rincón. En su crítica a Dámaso Alonso en 1972, escribe que "en la accidental coincidencia de la fetichisada obra en-sí y del a-histórico lector en-sí, la lectura se convierte en vivencia extática que participa del milagro de la comunión de los fieles, bajo las especies de la palabra escrita" (67-68). Dejar atrás ese rastro fetichizado y religioso de la lectura, presente incluso en la hermenéutica, será parte de su trascurrir a partir de esta década. Durante 1976-80, fue profesor en la Universidad Central y en el Posgrado del Instituto Pedagógico Universitario de Caracas. Allí, participó en el CELARG (Centro de Estudios Latinoamericanos Rómulo Gallegos), un centro de irradiación regional donde trabajó junto con otros intelectuales latinoamericanos destacados, tal como lo cuenta Hugo Achúgar (Acree 2005, 192).

Es precisamente allí donde se van a gestar los materiales que posteriormente serán compilados bajo el título El cambio actual de la noción de literatura y otros estudios de teoría $y$ crítica latinoamericana, publicado en 1978 por el Instituto Colombiano de Cultura. Esta serie de textos suponen, en efecto, un desplazamiento en las formas en que se pensaba la literatura latinoamericana y la función del crítico en el sistema extrauniversitario. Ya para entonces, según se puede leer en una reseña del libro de 1981, podía entreverse la lectura mayoritaria que iría a determinar la acogida de sus libros incluso hasta hoy:

El libro recopila seis ensayos - previamente expuestos y publicados - sobre literatura latinoamericana contemporánea vista desde una posición político-ideológica marxista materialista junto con algunas tesis de la escuela alemana de la "Estética de la Recepción" [i.e Hans Robert Jauss]. Estas circunstancias explicarían, por una parte, las reiteraciones y la diluida coherencia argumentativa a través del libro, y, por otra, la obsesiva beligerancia en contra de las corrientes teórico-metodológicas que el autor impugna como "inmanentistas", "ahistorizantes", "autonomistas". (Carreño Gallo 1981, 67)

Lo que se le escapa al reseñista es nada menos que la explosión del sistema de la literatura y la crítica en el continente, de la cual el libro de Rincón era como tal un síntoma - al 
tiempo que operaba como un sismógrafo de ese cuerpo social convulsionado. Nada menos, entonces, que la disputa contra el idealismo y la abstracción, por un lado, y la emergencia de la hermenéutica como cifra de época, por otro. Y es en dicha mezcla entre materialismo y hermenéutica donde el libro de Rincón adquiere su singularidad. Los efectos de dicha singularidad fueron de índole diversa: con ese libro Rincón no sólo juega un papel crucial en la elaboración de la problemática del testimonio en los Estados Unidos (así lo reconoce John Beverley), sino que de ahí en adelante buena parte de su obra estará dedicada al estudio de testimonios figurativos (imágenes) como fuentes históricas en la estela de Aby Warburg, Erwin Panofsky y Carlo Ginzburg. Basta ver sus trabajos sobre imágenes barrocas y el neobarroco.

El reseñista se queja asimismo de que su "sintaxis bastante compleja, truncada por marañas incidentales, así como citas en portugués y expresiones en alemán, exigen un esfuerzo adicional a cualquier lector profano". La extrañeza frente al portugués es justamente sintomática del olvido que había frente a la literatura brasileña en muchas críticas literarias. Lo que en esa época se leía como una suerte de ofensa al lector (ahora, ¿por qué habría que invocar un lector por el cual sentir compasión?), años más tarde se va a analizar como un componente crucial del vasto campo de los estudios de traducción. La reseña reitera aquello que se repetirá en muchos lectores de Rincón, señalando "la imposibilidad de una secuencia lógica - debido a la fragmentación de los ensayos que integran el libro-_" (Carreño Gallo 1981, 271).

Esta percepción de fragmentación, entendida como algo negativo, ha operado como una de las razones para el olvido de la obra de Rincón, pues, dicen algunos, ¿cómo leer algo disperso y sin sistema? No obstante, propongo que precisamente esta fragmentación, entendida como diferencia o heterogeneidad, es la que, en términos afirmativos, va a marcar su duelo con las diversas formas de la representación y sus llamados a la unidad y a la identidad.

Esa tensión va a alcanzar uno de sus puntos políticos y éticos máximos durante la estancia de Rincón en Nicaragua, donde fue asesor entre 1980 y 1986 de Ernesto Cardenal, entonces Ministro de Cultura. Allí, además, junto con Dieter Eich realizó una serie de entrevistas a 95 contras nicaragüenses en uno de los episodios más aterradores de la contra-insurgencia y la acción encubierta en las Américas. El libro mostraba la brutalidad de uno de los rasgos predilectos de la representación: la soberanía. A Nicaragua volverá muchos años después, al final de su vida, con un breve pero impresionante texto sobre el diferendo marítimo de Colombia con ese país. Para ello nos presenta un retrato fotográfico de 2012 del entonces presidente colombiano Juan Manuel Santos, nieto segundo de un expresidente, quien aparece rodeado, en una perversa repetición, de varios de los demás ministros y expresidentes de su generación. Si proyectáramos sobre esa fotografía una suerte de maqueta subyacente imaginaria, siguiendo el análisis de Rincón de la génesis de la superficie pintada del retrato de Pablo Morillo (composición, agregados, bocetos), encontraríamos en esa foto-retrato una instantánea de una genealogía anti-nietzscheana, entendida no como procedencia sino como linaje, como tronco - la mismidad, el "eso mismo" carcomiéndose, re-trayéndose, en una suerte de repetición sin diferencia- $(2014 c, 320)$.

Este período nicaragüense de Rincón, que aún falta por estudiar, es la antesala de su vuelco definitivo hacia la reflexión sobre el posmodernismo y la posmodernidad. Para 1986, Rincón pudo plantear que el problema del tiempo no era sólo el de las generaciones o las periodizaciones, las fases. La literatura y su historia no era sólo una cuestión intra-literaria, de causas o factores ideológicos externos: estaba envuelta en la serie de crisis que habían sacudido a la conciencia histórica $-\mathrm{y}$ a sus estratos inconscientes. Es decir, que literatura e historiografía eran terrenos disímiles pero contaminados entre sí:

La exigencia en cuestión es la de hacer, justamente, historia de la ciencia, de las formas adoptadas por la conciencia histórica y su articulación en diversos proyectos historiográficos o ensayísticos... para determinar el carácter de la historiografía literaria latinoamericana. (1986, 15-16)

Por historia de la ciencia, Rincón no se refería, por supuesto, a una literatura o crítica literarias de corte objetivo, genético, sino al campo transnacional abierto entre otras, por tres figuras clave: Michel de Certeau — quien visitó diversos países latinoamericanos, salvo, claro, Colombia-; y Georges Canguillem y Michel Foucault (a quienes Rincón había traducido al español), "en las tradiciones de las historischen Disziplinen (Prusia) o de la Science de l'homme (Francia), en cuanto concepciones la ciencia y como formas de asumir lo que Foucault describió como crisis de la categoría de la representación" (1986, 16-17).

Analizar el diagrama latinoamericano en términos de crisis de la representación y no del juego de identidades — nuestroamericanismo - es lo que va a potenciar su proyecto y a causar más incomodidad entre la crítica (mas, ¿no será acaso este tipo de interrogación sobre la representación la que recogerán los estudios culturales, poscoloniales y subalternos latinoamericanos?). La intervención central que marca la bisagra con su proceso anterior centrado en la experiencia, el tiempo y la historia de los conceptos, será la ponencia "Modernidad periférica y el desafío de lo postmoderno: Perspectivas del arte narrativo latinoamericano" en Dartmouth en 1988. En esa ponencia, presentada en el simposio "Latinoamérica: Nuevas Direcciones en Teoría y Crítica Literarias", Rincón planteaba algo cuya vigencia entonces y ahora no cesa de persistir:

Uno de los problemas irritantes en el tratamiento de la literatura de la modernidad por parte de la crítica 
afecta - y tanto más de los propios autores: cfr. Mario Vargas Llosa y Carlos Fuentes-, es la irrebasable dificultad de argumentar a no ser sobre la base de antinomias: texto tradicional/texto moderno, compromiso político/compromiso literario, función afirmativa/función emancipatoria de la literatura. Dentro de ese juego repetitivo y perseverante de dicotomías esa crítica llega a ontologizar ahistóricamente fenómenos recientes o actuales del proceso de comunicación literaria como es, por ejemplo, el de la polarización: alta literatura/literatura de masas. Cualquier puesta en cuestión que consigue llegar a arriesgar, únicamente es imaginable entonces para esta práctica crítica desde el ángulo de uno de esos elementos, y no desde el punto de vista de un cambio de las relaciones (y de la función) literarias (y sociales). (1989, 66)

Este tipo de interrogación al modo ser dialéctico, marcaba ya la posibilidad de ubicarse, o de ser ubicado, fuera de lugar. Pues, dados los consensos explícitos e implícitos que autoriza la academia, ¿cómo habría lugar para alguien que, en 1993, en la destacada colección titulada "Postmodern Debate in Latin America" por John Beverley y José Miguel Oviedo, usaba a Borges como "centro periférico del posmodernismo"? Borges era una suerte de "posibilidad inaceptable" - y lo seguirá siendo, pues "la posibilidad de la repetición construida sobre la (di)similitud es su corolario" (Rincón 2004a, $15)$.

Rincón mismo nos da una pista sobre ese lugar imposible cuando recuerda la valoración que formuló Ángel Rama sobre Borges en la discusión de las imposibilidades del "qué hacer con Borges" en la década del 50 del siglo XX. "No tiene entonces por qué sorprender", escribe Rincón (2004a), "la manera tan enfática como Ángel Rama situaba en 1959 a Borges, desde la Revista Nacional de Montevideo, dentro de su particular visión de la historia de la literatura y los vínculos que imaginaba con el devenir histórico" (50):

'Él [Borges] ha socavado la tradición realista de las letras españolas, pero su tarea ha sido de simple destrucción y nada ha hecho para imponer paralelamente la creencia en un trasmundo fantástico que legitime sus historias fantásticas. Ha jugado con él, pero a pesar de ser un creador de cuentos fantásticos ha dejado indemne el mundo realista que sostiene la literatura realista'. (2004a,50)

Aquí retoma Rincón: "Es notable que ni por un momento hayan pensado en considerar a Borges en relación con Joseph Conrad, Edward M. Foster, James Joyce o Thomas Stearn Eliot, con los acentos sinceros y honestamente asqueados ante su sociedad y las instituciones que la definían" (2004a, 50). A los pocos años de que Rama escribiera eso, Gilles Deleuze, Michel Foucault y Jacques Derrida usarían los escritos del argentino con resultados y alcances notablemente dispares a los del crítico uruguayo. "En el caso de la obra de Jorge Luis Borges", escribe Rincón en la que es su revaloración de La no simultaneidad de lo simultáneo y de la peculiar respuesta a los reseñistas de ese libro,

entre 1964 y 1969 la versión particular de ella estructurada por Roger Caillois como editor, había contribuido en Francia al auge de las teorías de la lectura, y al mismo tiempo fue celebrada por Foucault como origen de su proyecto arqueológico. Jacques Derrida, por su parte, la involucró en deconstrucción de la metafísica, con la demonstración de la represión de la lógica de la différence y el suplemento en las teorías del signo. Gilles Deleuze, finalmente, reivindicó dentro de su crítica al platonismo el concepto de simulacrum, tan virulento en la reflexión de Borges, y ante la infertilidad reinante en el campo de la historia de la filosofía, propuso a Borges como modelo de una nueva práctica de ella. (Rincón 2006, 108)

En efecto, en el que es quizás el libro más bello, fantástico y filosóficamente promiscuo del siglo XX, Diferencia y Repetición de Deleuze de 1968, se puede entrever una filosofía en búsqueda de nuevos medios expresivos, de nuevas atmósferas: "un libro de filosofía debe ser por un lado una especie muy particular de novela policial y por otro una suerte de ciencia ficción” (Deleuze 2002, 17). ¿Estaba la crítica literaria latinoamericana lista para mezclar sus textos con ficciones o relatos policiales? Es decir, ¿estaba preparada esa crítica para leer en reversa, esto es, leer la crítica desde la literatura?

$* * *$

Ya desde su ponencia en Dartmouth en 1988, al lado de Borges, Rincón situaba a García Márquez como aquel fabulador que había sido capaz de desplazar el centro del globo, o al menos mostrar su inevitable movilidad. Pero ello era necesario evitar plantear falsos problemas, como el de la identidad latinoamericana. Por ejemplo en su ponencia presentada en el mismo coloquio, el crítico Nelson Osorio persistía en "proponerse un estudio crítico del pasado, de la historia, de la tradición, de las 'raíces"” (Osorio, 293).

Rincón, entre tanto, había encontrado en la dupla posmodernidad/posmodernismo otra manera de plantear y pensar la situación latinoamericana. Por supuesto, no es que fuera el único ni el primero en plantearse esa dupla en América Latina. Pero sí fue uno de los pocos que, desde la crítica literaria, la planteó desde el ángulo de la crisis de la representación. No obstante, cabe anotar que, a diferencia de lo que sostiene Rincón, para quien "del lado latinoamericano ni siquiera se había tomado nota de la existencia del debate postmoderno en filosofía" (1995, 40), la filosofía minoritaria en América 
Latina sí lo había hecho - mas no así la crítica literaria mayoritaria. Cabe aquí decir que, más que una prosa barroca sobrecargada de name dropping, como arguyen muchos de sus críticos, en Rincón sí hay un notorio punto ciego en sus valoraciones: las diversas vías de experimentación a lo largo de América Latina con formas menores de la filosofía y el arte.

La cuestión era entonces que esa dupla (posmodernidad/ posmodernismo) era percibida mayoritariamente como un asunto bien de moda intelectual, bien de imposición imperialista. De ahí que, en el mismo coloquio de 1988, George Yúdice abriera su intervención señalando "el carácter simulacional del discurso posmoderno" (Yúdice 1989, 106). Precisamente ahí yace la divergencia del proyecto de Rincón, pues se instala en el mundo de lo virtual y el simulacro - que es el nuestro-, en el cual la repetición y la diferencia sustituyen a la identidad y la contradicción. Mas "no se trata de reduplicar una realidad autoevidente, autolegitimada, a partir de la existencia de un lazo natural entre las palabras y las cosas, el mundo y la novela, sino en otra cosa: en repetir los libros" (Rincón 1999, 201). Repetición, claro, de lo desemejante: algo que Rincón también encontrará en Alemania, en la lectura que Hans Robert Jauss hizo de las ficciones de Borges: "la no identidad de lo repetido en la distancia temporal de la repetición: dos veces la misma cosa — con mediación de una distancia temporal-no es la misma cosa" (Rincón 1995, 71).

Esta repetición de lo heterogéneo es lo que lanza un ataque al sentido en dos direcciones: contra el "buen sentido" (hay un sentido único, y determinable) y contra el "sentido común" (como reconocimiento de lo que es idéntico). Quien determina y asigna lo único sería el crítico; y, quien reconoce, el autor. Más allá y más acá del sentido, había ese algo más que no era del orden de la representación y la identidad sino de la diferencia: el acontecimiento. Eso es lo que no era posible reconocer desde las escuelas generacionales, o estructuralistas. Una cosa era entonces una literatura abierta a lo incierto y lo acontecimental (Borges, por ejemplo). Otra, muy distinta, era una crítica literaria capaz de esa apertura. Y allí es donde la crítica de Rincón halla su fuerza - y su rechazo por parte de tantos lectores - pues atenta, también, contra el buen sentido y el sentido común del crítico.

Entrar de lleno al debate del posmodernismo (utilizando como hace Rincón a John Barth, por ejemplo) hubiera implicado viajar con las novelas de Gabriel García Márquez y los textos de Borges a Norteamérica, pues "las ficciones latinoamericanas, ante todo las de Borges y de modo determinante las de García Márquez, fueron asimiladas desde finales de los sesenta y los setenta, como autoritativas e inaugurales, por la ficción postmoderna norteamericana" $(1995,47)$. Eso, en efecto, impediría acentuar nuestra presunta "diferencia" latinoamericana. Y, de paso, por un lado, "raptar" a García Márquez del halo del boom latinoamericano (como lo hizo John Barth). Por el otro, cargar con el estigma de Borges implicaba no sólo uno adicional —el estigma del posmodernismo - sino, vaya barbaridad, jel del posestructuralismo! El intento de Rincón era, si se quiere, un ataque a la dialéctica. Y a los juegos identitarios, de reconocimiento, de las prácticas del latinoamericanismo predominante.

Impugnar ese arte dialéctico de la identidad tendrá un primer momento de cristalización en 1995 con la publicación de su libro La no simultaneidad de lo simultáneo. Posmodernidad, globalización y culturas en América Latina. Ya el solo título anunciaba un desorden de la que fue una de las gramáticas dialécticas más sugestivas del siglo XX: el marxismo de Ernst Bloch, que con su formulación de la simultaneidad de lo no simultáneo había tratado de desentrañar la coexistencia de destiempos y anacronismos presentes entre fascismo y modernidad en Alemania. Al invertir la fórmula, Rincón daba cuenta no sólo de un cambio de época.

Recordemos también que la fórmula de Bloch emerge, primero, en la historia del arte en Alemania con Wilhelm Pinder, en un contexto de afinidades con el nazismo (Schwartz 2001). Si bien la fórmula original de Pinder en 1926 es la misma de Rincón va a emplear años después ( $L a$ no simultaneidad de lo simultáneo), la repetición ahora difiere: interrumpir esa simultaneidad en tanto no simultaneidad implicaba, entre otras cosas, que el texto, la escritura, era incapaz de captar esa simultaneidad, pues, lo sabía Borges por lo menos desde el Aleph, el mundo no es el texto: "En el aleph, en la pequeña esfera, se puede contemplar el mundo, lo que acontece en el mundo de modo simultáneo. El lenguaje, la literatura, no puede expresar esa totalidad o esa simultaneidad, porque él es sucesivo" (Gutiérrez Girardot 1998, 97). A su vez, con esa inversión, Rincón iba a tematizar no solo la cuestión del tiempo, sino también la del espacio. No sólo estaba intentando responder a la pregunta ¿qué es la posmodernidad? formulada por Lyotard, y a las insinuaciones de Jean Baudrillard en Cultura y simulacro. Su discusión explícita era con las formulaciones de Fredric Jameson sobre la lógica espacial de la posmodernidad ante la crisis de la historicidad: "La estrategia que busco desarrollar aquí en relación con las teorías posmodernas y las teorizaciones sobre el postmodernismo en oposición a él [Jameson], es de intervención y de interferencia desidentificadora" $(1995,75)$. Por ello uno de los capítulos de su libro estará dedicado a la arquitectura y las metrópolis latinoamericanas. El predominio de lo temporal (simultaneidad, heterogeneidad), nos recordará una década después, es una obsesión moderna por excelencia, que deja de lado lo espacial (Rincón 2006, 122). Pero lo más interesante es que el ángulo de Rincón pasa tanto por las implicaciones entre el territorio y el mapa de Borges, como por Foucault, quien "describía en ese tiempo la época contemporánea [1967] como la 'época del espacio', de manera que se viviría "en la época de lo simultáneo, de las yuxtaposiciones, en la época de lo cercano y lo lejano, de lo contiguo y lo separado" $(1995,37)$. 
El tono del libro suscitó desconcierto por su carácter inestable y por su presunta opacidad. "El lector que se aproxime al libro buscando claridad se verá decepcionado. Claridad no hay”, escribió un reseñista (Zuleta 1997). Una mirada distinta presentó Román de la Campa (1996), desde Norteamérica, celebrando el texto de Rincón como un trazo de uno de "los nuevos cartógrafos latinoamericanos", junto con Néstor García Canclini y Beatriz Sarlo, por "un nuevo rigor mucho más abarcador" (698-699). De todas las reseñas aparecidas sobre el libro de Rincón, en buena parte aturdidas por esa "fragmentación" e "imposibilidad de una secuencia lógica" que ya señalaba la reseña de 1981, es quizás la de Ellen Spielmann (1996) la que mejor captura la novedad de este libro: éste descentra el debate sobre lo posmoderno" precisamente porque es un libro posmoderno (Spielmann, 942). Medirse en términos posmodernos - no dialécticos - con el posmodernismo fue quizás lo que tanto desconcertó de este libro. Retrospectivamente, en lugar de fragmentación, podemos recuperar el análisis que hará Rincón sobre Borges al recurrir a la palabra inglesa coat, que "es tanto colcha de retazos de tela como cento o centón, obra hecha con frases completas o versos de otras obras, vueltos a combinar" (Rincón 2004a, $15)$.

La publicación de La no simultaneidad, un libro con sus altos y bajos, va a marcar, a mi modo de ver, el momento en que en diferentes academias se empieza a alterar la valoración acerca de su trabajo. Los caminos, entonces, se separarán. Ese cambio, sin embargo, venía ya en camino a raíz de la dupla posmodernidad/posmodernismo aludida atrás. Un año antes de la publicación del libro, en una entrevista hecha a Antonio Cornejo Polar en 1996, Ingrid Galster (2016) hablaba de "la aceptación progresivamente incondicional [del posmodernismo], actitud que tomó Carlos Rincón también presente en Cerdeña," donde se realizó el simposio en honor a Roberto Fernández Retamar en 1990. Las otras dos posiciones eran, según Galster, la del rechazo absoluto al posmodernismo (la intervención de Nelson Osorio en Dartmouth en 1988), y la de un "posmodernismo muy peculiar que se remite a la razón comunicativa de Habermas y favorece como género la novela testimonio", como en el trabajo de Yúdice (Galster 2016, 105). Sin entrar a discutir el esquema de Galster, pareciera que las dos últimas posiciones - con variaciones, adendas, mezclas - fueron las que permanecieron como dos de las tendencias mayoritarias.

En la versión del rechazo absoluto, a diferencia de lo que podía ser la práctica común del crítico literario latinoamericano en lucha contra la injusticia y la opresión, Rincón aparecía como un ilustrado metropolitano desanclado de esa realidad, indiferente al sojuzgamiento de los poderes globales sobre las periferias. Pero eso es ir muy rápido. Al inicio de este texto mencionaba que los textos de Rincón son materiales para pensar: al ubicarse en la crisis de la representación. Es decir, no como un modo de acceso a la verdad, sino a los problemas mismos, como recuerda Enrique Asiáin. De ahí el desconcierto de algunos lectores: pero, y ¿dónde está el juicio?, ¿dónde la sanción?, y ¿dónde el veredicto? Por eso es que La no simultaneidad, tenía una suerte de doblez, que fue el texto redactado ese mismo año por Rincón, y publicado cuatro años después, con ocasión del septuagésimo aniversario de García Márquez: García Márquez, Hawthorne, Shakespeare, De la Vega \& Co. Unltd. Aparte de ser una suerte de ventana para observar el taller de su lectura y escritura, el libro posee una velocidad diferente en su escritura a la de $L a$ no simultaneidad, fruto de un par de exposiciones orales. Es un pliegue en torno a cómo construir problemas en el campo de la crítica literaria; uno de sus capítulos se llama, de hecho, “¿Por qué leer? ¿Cómo leer?”. Ese libro es como un cuaderno de aprendiz.

También es ir demasiado rápido, pues desde finales de los ochenta Rincón venía notando el papel de Borges y García Márquez en la construcción de las ficciones postcoloniales de los setenta y los ochenta. "El realismo mágico se convirtió en un nexo cartográfico entre el postmodernismo y las ficciones poscoloniales, dentro de los propósitos de Remapping adelantados en la tensión entre culturas locales y cambio global" $(2006,112 ; 1995,68)$. Es por eso que la valoración del ángulo político de este ataque a la representación ejecutado por Rincón debe salir del modelo dialéctico. Es decir, debe enfrentarse a los textos de Rincón en su propio terreno, para evaluar si efectivamente, partiendo de los términos en que construye el problema, este es lo suficientemente relevante y consistente.

Para ello, resulta indispensable la lectura de dos de sus últimos libros de autor publicados en Colombia, Íconos y Mitos Culturales en la Invención de la Nación en Colombia (2014) y Avatares de la memoria cultural en Colombia. Formas Simbólicas del Estado, Museos y Canon Literario (2015).

En ambos libros, como dijimos al principio, Rincón ensaya escribir fragmentos de lo vivido en Colombia desde el ángulo de una estética política. No será casual que años después de esa primera reseña de 1981, el historiador Renán Silva (2017), en su reseña del libro Avatares de la memoria, tome prestada la expresión que Lucien Febvre utilizó para analizar el trabajo del polémico Julien Benda (un "volúmen con formato de novela"): "Historia de tesis". Esto es, un clamor, hecho a partir de deducciones, un llamado a-sistemático. Lo clave aquí, no obstante, es el estilo de Rincón, el moverse entre lo macroscópico y lo microscópico; el juntar los rasgos de una época con los pormenores, la analítica transversal con la anécdota, el archivo y el concepto. Por esta razón, la cuestión es que, más que a Benda, Rincón quizás se acerca al tono de alguien como Carlo Ginzburg. En todo caso, si estamos frente a una "novela" al leer los textos de Rincón (y ¿por qué no?), sería cuando menos una novela psicoanalítica: multicausal, polivalente, traidora. En su discurso de apertura de la Cátedra Michel de Certeau en Bogotá en 2003, Rincón recordaba la frase del sacerdote jesuita: "Si se quiere analizar, en 
su sutileza formal, las prácticas cotidianas, leamos novelas" (2004b, 72).

Se trata en esos libros no sólo en situar a Colombia en un plano global, sino en algo que va más allá de contar el pasado: las relaciones entre literatura e historia apuntan no sólo a contar, narrar o escribir la historia, sino a "elucidar las operaciones temporales (causalidad, cruzamiento, inversión, condensación, etcétera)" (De Certeau 2007, 46). Novela, entonces, si como dice Michel de Certeau, "la literatura es el discurso teórico de los procesos históricos" (41): es decir, la "novela histórica" de corte psicoanalítico, con su recurso a la tragedia y a la retórica, es la que habilita la crítica de la idea nacional (como "desmembramiento").

El caso de Simón Bolívar es aquí crucial como imposibilidad de trazar la identidad del retratado - y de lo retratado: la nación imposible. "Tres décadas después de haber fallecido Simón Bolívar, la ausencia de retratos que restituyeran sus facciones ya formaba parte de la leyenda sobre sus desventuras" (Rincón 2002, 24). Esto lo escribía Rincón a inicios del siglo XXI, años antes de toparse con el destacado fotógrafo Jorge Mario Múnera en 2005 en el Centro Rockefeller de Estudios Latinoamericanos de la Universidad de Harvard. El motivo fue, según lo cuenta Múnera, publicar una serie de libros sobre algunos de los trabajos ganadores del Programa Art Forum. Retratos de un País Invisible fue la serie en la que, junto con textos de Rincón y otros más, apareció la foto de Múnera del Bolívar derrotado, su rostro fracturado, des-hecho: a la vez, signo del desmembramiento mismo de Colombia.

Entonces, si estamos frente a una novela de corte psicoanalítico, la pregunta ya es otra: ¿es una buena o una mala novela?, ¿evalúa de manera sugerente los síntomas del cuerpo social que disecciona? Si esto es así, estamos ante la posibilidad de que las "novelas psicoanalíticas" de Rincón se alejen de las tendencias hostiles a la vida que Nietzsche halla en los modos de vida y de escritura convencionales del hombre moral. Estamos ante un contador de relatos y fabulaciones, lector de vestigios y nimiedades, tal como el historiador italiano Carlo Ginzburg (2008) definió el arte de lo infinitesimal: la del buscador de "síntomas (en el caso de Freud), indicios (en el caso de Sherlock Holmes), rasgos pictóricos (en el caso de Morelli)" (Ginzburg, 192). ¿Cabía un estilo de crítica así en el ecosistema crítico latinoamericano?

Recordar y olvidar a Rincón tal vez pase por desenrollar esa pregunta. Y por seguir halando algunos hilos que dejó sueltos como caminos abiertos en su experimento transmedial - como el proyecto de una historia de la estética moderna en Colombia (2018b). Recordemos que el único Moreli posible que ha habido en Colombia ha sido Ángel Cuervo, quien firmaba como "Moreli" su Conversación Artística de 1887, en la cual, nos cuenta Rincón, ignoraba por completo la irrupción de la fotografía y las pinturas impresionistas (2014a, 208; 215). Prosigamos diciendo que, si nos atenemos a los pocos estudios dedicados al trabajo de Rincón, y a su invisibilidad en buena parte de los programas literarios a lo largo de las Américas, podemos conjeturar que estamos ante la subordinación de uno de los experimentos transmediales más fecundos en la crítica literaria latinoamericana reciente. Afortunadamente, sabemos con De Certeau que el olvido no es pasividad o pérdida, sino una acción de fuerzas sociales contra el pasado. Veremos si esa correlación de fuerzas se altera en el futuro cercano.

\section{Obras citadas}

Acree, William. 2005. "Conversación con Hugo Achugar”. A contracorriente. 3(1):190-197.

Carreño Gallo, Luis Antonio. 1981. “Carlos Rincón. El cambio en la noción de literatura. Reseña”. Acta Poética 3: 267-271.

De Certeau, Michel. 2007. "La 'novela' Psicoanalítica. Historia y Literatura." Historia y Psicoanálisis. Entre Ciencia y Ficción. México D.F. Universidad Iberoamericana.

De la Campa, Román. 1996. "Latinoamérica y sus nuevos cartógrafos: discurso postcolonial, diásporas intelectuales y enunciación fronteriza." Revista Iberoamericana. LXII(176-177): 697-717.

Deleuze, Gilles. 2002. Diferencia y repetición. Buenos Aires: Amorrortu.

Galster, Ingrid. 2016. "Algunas preguntas a Antonio Cornejo Polar sobre teoría y crítica literaria latinoamericanas". El lugar de la crítica. Conversatorios y entrevistas. Editado por Mauro Mamani Macedo. Lima: Centro de Estudios Literarios "Antonio Cornejo Polar". 
Ginzburg, Carlo. 2008. "Indicios. Raíces de un paradigma de inferencias indiciales.” Mitos, emblemas, indicios. Morfología e historia. Barcelona: Gedisa.

Gutiérrez Girardot, Rafael. 1998. "Jorge Luis Borges." Jorge Luis Borges. El gusto de ser modesto. 7 ensayos de crítica literaria. Bogotá: Editorial Panamericana.

Rincón, Carlos. 1972. “Lectura y ciencia literaria en Dámaso Alonso.” Bulletin Hispanique. Tome 74, N¹-2: 61-91.

---. 1978. El cambio actual de la noción de literatura y otros estudios de teoría y crítica latinoamericana. Bogotá: Instituto Colombiano de Cultura.

—. 1986. "Historia de la Historiografía y de la Critica Literarias Latinoamericanas Historia de la Conciencia Histórica". Revista de Crítica Literaria Latinoamericana. Año 12, No. 24, Modernidad y Literatura en América Latina: 7-19.

---. 1989. "Modernidad periférica y el desafío de lo postmoderno: perspectivas del arte narrativo latinoamericano". Revista de Crítica Literaria Latinoamericana, 15(29), 61-104.

---. 1993. “The peripheral center of postmodernism: On Borges, García Márquez, and Alterity”. Boundary, 2, 20(3): 162-179.

---. 1995. La no simultaneidad de lo simultáneo. Posmodernidad, globalización y culturas en América Latina. Bogotá: Universidad Nacional de Colombia.

---. 1999. “'Del amor y otros demonios', páginas 9 a 11; o, sobre la reescritura de las 'Foundational fictions' norteamericanas”. Revista de Crítica Literaria Latinoamericana. Número dedicado al homenaje del Instituto Internacional de Literatura Iberoamericana a Antonio Cornejo Polar: La Trayectoria Intelectual de Antonio Cornejo Polar, 25(50): 199-224.

---. 2002. "Las imágenes en el texto: entre García Márquez y Roberto Bolaño. De la alegoría del tiempo al universo de las imágenes". Revista de Crítica Literaria Latinoamericana, 28(56): 19-37.

—. 2003. "Las tres Atenas". En: ReVista. Harvard Review of Latin America, Vol. II, No. 3: 35-39.

—. 2004a. "Mapa, distopía, simulacro: El Inmortal, de Jorge Luis Borges". Borges, lo sugerido y lo no dicho. Bogotá: Siglo del Hombre Editores.

---. 2004b. La irrupción de lo impensado. Discurso de inauguración de la Cátedra Michel de Certeau. Bogotá: Instituto Pensar: 57-74.

---. 2006. "Sobre el debate acerca del postmodernismo en América Latina. Una revisión de La no simultaneidad de lo simultáneo. Postmodernidad, globalización y culturas en América Latina”. Cartografías y estrategias de la 'posmodernidad'y la 'postcolonialidad'en Latinoamérica. 'Hibridez'y 'globalización'. Madrid: Iberoamericana.

---. 2014a. “1885: La Atenas Suramericana En La Capital de La Modernité.” Íconos y Mitos Culturales En La Invención de La Nación En Colombia. Bogotá: Universidad Javeriana.

---. 2014b. "El ícono negativo por excelencia. Celebración y escarnio del Conde de Cartagena, General Pablo Morillo.” Íconos y Mitos Culturales En La Invención de La Nación En Colombia. Bogotá: Universidad Javeriana.

---. 2014c. “En Lugar de Un Epílogo: Una Fotografía Para Recordar.” Íconos y Mitos Culturales en la Invención de la Nación en Colombia. Bogotá: Universidad Javeriana.

---. 2015. "La necesidad de investigación básica: sobre el mito patriótico originario de los colombianos y algunas de las estrategias que lo flanquean.” Avatares de La Memoria Cultural En Colombia. Formas Simbólicas Del Estado, Museos y Canon Literario. Bogotá: Universidad Javeriana.

- 2018a. María la de El Paraíso. El juicio en televisión de la novela de Jorge Isaacs: los ecos y el dolor de lo que pudo haber sido y no fue. Bogotá: Pontificia Universidad Javeriana. 
---. 2018b. "Posfacio. Informe Para Una Academia: Sobre Un Proyecto de Libro acerca de Estética Moderna en Colombia." Fealdad, Gracia y Libertinaje. Estética y Modernidad En El Pensamiento Colombiano [1940-1960], editado por Paola Montero et al. Bogotá: Universidad Nacional de Colombia.

Schwartz, Frederic J. 2001. "Ernst Bloch and Wilhelm Pinder: Out of Sync”. Grey Room, No. 3 (Spring): 54-89.

Silva, Renán. 2017. "Sobre el fracaso de una nación. Avatares de la memoria cultural en Colombia. Formas simbólicas del Estado, museos y canon literario. Carlos Rincón”. Boletín Cultural y Bibliográfico. LI(93): 139-40.

Spielman, Ellen. 1996. "El descentramiento de lo posmoderno”. Revista Iberoamericana. LXII(176-177): 941-952.

Yudice, George. 1989. “¿Puede hablarse de postmodernidad en América Latina?” Revista de Crítica Literaria Latinoamericana, 15(29), 105-128.

Zuleta, Rodrigo. 1997. "Lecturas atragantadas". Boletín Cultural y Bibliográfico. XXXIII(41). Disponible en: https:// publicaciones.banrepcultural.org/index.php/boletin_cultural/article/ view/1829. 